\title{
Mobile learning: from research to practice to Impact Education
}

\author{
Mohamed Ally \\ Athabasca University, Canada
}

\section{Introduction}

Recently there has been considerable interest in the use of mobile technology in education, although the technology is still evolving. The question is why the sudden interest, especially in countries that have large-scale implementations of mobile technology in education. Some countries have undertaken initiatives to implement the use of tablet computers and smart phones so that their citizens can use the technology to learn and to connect to the world. In the Gulf region, the United Arab Emirates (UAE) is taking a leading role in implementing the use of high-end tablets for students to learn (Gitsaki et al., 2013; Kamali, 2013). The State of Qatar is taking a leadership role in developing and researching mobile learning in the workplace. A current project funded by the Qatar Foundation ${ }^{1}$ is investigating the use of mobile learning to train employees on workplace English in the oil and gas industry (Ally \& Samaka, 2013). Countries elsewhere with similar initiatives include South Korea, Brazil, Thailand, and India. Some countries are going one step further by digitizing learning resources such as textbooks, manuals, etc for access on mobile technologies. For examples, South Korea is planning to digitize the whole K-12 curriculum for tablet computers by 2015 (Mims, 2011): students will take a tablet with the electronic materials to school rather than heavy textbooks and manuals. These countries and other countries around the world are realizing that the use of mobile technology is a way to educate all citizens and some countries are realizing that having citizens connected to the internet using emerging technologies such as mobile technology, is an economic advantage. However, more research is needed to determine how mobile technology impacts education so that mobile learning initiatives can follow proper practice in their implementation. This paper will provide an overview of the global use of mobile technology and mobile learning, discuss research on mobile learning that should be conducted, outline the benefits of mobile learning, and discuss the challenges when implementing mobile learning as well as how to tackle these challenges.

\section{Use of mobile technology and mobile learning}

The number of mobile subscriptions will reach the seven billion mark in 2013 , which will be higher than the human population (Faille \& Morrison, 2013). As smart phones and tablets become more use-friendly and powerful, they will tend to replace desktop and notebook computers: it is estimated that the number of smart phones and tablets sold in 2016 will be 1.34 billion and 384 million respectively (Faille \& Morrison, 2013). However, the ownership of mobile technologies by students and teachers does not guarantee their use in education. There must be proper training for teachers on how to use the mobile technology, how to design mobile learning materials and how to access existing learning materials. It is important to follow good learning design principles for mobile learning, especially when designing for different cultures (Wang \& Shen, 2012). Learners must be trained on how to use the mobile technology and how to access the learning materials. Some studies (Corbeil \& Corbeil, 2011; Mahat et al., 2012; Ng

\footnotetext{
${ }^{1}$ The project is funded by the Qatar Foundation: Qatar National Research Fund - NPRP Grant \# 4 - 125 - 5 - 016.

Ally, M. (2013). Mobile learning: from research to practice to Impact Education. Learning and Teaching in

Higher Education: Gulf Perspectives, 10(2). http://Ithe.zu.ac.ae
} 
\& Nicholas, 2012; Park et al., 2012; Taleb \& Sohrab, 2012) have shown that learners are ready for mobile learning; however, more research has to be conducted to investigate the factors affecting the acceptance of mobile learning by both teachers and learners (Cheon et al., 2012). Once these factors are identified then intervention strategies can be used to encourage acceptance of mobile learning by teachers and learners.

Educators must capitalize on the increasing use of mobile technologies, which is placing the technology in the hands of the learner, to design and deliver learning materials for access by learners. Citizens around the world currently spend time playing games, searching for information, socializing, reading the news, etc. rather than using the mobile technology to learn (Bosomworth, 2013). Teacher training and professional development programs must train teachers and professors to use mobile technology in education; also, research is needed on the role of the teacher in a mobile world and how teachers can use mobile technologies effectively for teaching and learning (Aubusson et al., 2009). Cochrane (2010) investigated the success factors when using mobile learning and found that the critical factors include: good pedagogical design of the learning materials, links between mobile course elements and course assessment, the teacher modeling the use of the mobile technology, formative feedback to learners, and the appropriate selection of the mobile technology, including the software, for the delivery. Similar studies should be conducted on the large-scale mobile learning initiatives that are being implemented around the world to determine the success factors of these large-scale mobile learning initiatives.

Mobile technologies are being used by citizens for many activities and to complete many tasks. They use the same device to socialize, to shop (shop in the pocket), to bank (in the pocket banking), to access information (library in the pocket), etc. Learners can also use the same mobile technologies for informal learning and to learn outside the classroom (Cavus \& Uzunboylu, 2009; Jones et al., 2013; Lai et al., 2013; Terras \& Ramsay, 2012). Educators need to design learning materials for delivery on mobile technology so that there is learning in the pocket and on the go (Ally, 2009). The multimedia features, the ability to develop interactive learning materials and the capability to learn from any location make the use of mobile technology a potential tool to teach people with special needs (Fernández-López et al., 2013). Mobile technology is a powerful tool for learning especially when it uses the multimedia and interactive capabilities of the technology (Yen et al., 2012).

Quinn (2010) identifies "four C's" (Content, Compute, Capture and Communicate) to analyze the value of mobile technology for learning. The mobile technology can be used to deliver the Content, including multimedia content. The teacher can use the Computing power of the mobile technology to develop simulation and games and can prompt the learner for data and then process the data. The learner can Capture information for learning and sharing using features such as camera, audio, GPS, sensors, etc. The Communication features of the mobile technology allow the learner to communicate with other learners and with the teacher and to share information. In addition to these four C's, learning management systems on mobile devices allows the teacher to Coordinate the learning by tracking the learner's progress, style of learning, learner problems, etc. and prescribing the appropriate learning activities for the learner. Students are already familiar with the mobile technologies since they use them to browse, to play games, to socialize, to take photos and search for information, etc (Kinash et al., 2012). They should be encouraged to use mobile technology to access learning materials.

\section{Research on mobile learning}

Much of the research to date on the use of mobile learning has looked at student satisfaction in using mobile technology, and these studies have reported that students like the flexibility of using the technology (Pollara \& Kee Broussard, 2011). Only limited studies have looked at whether mobile

Ally, M. (2013). Mobile learning: from research to practice to Impact Education. Learning and Teaching in

Higher Education: Gulf Perspectives, 10(2). http://lthe.zu.ac.ae 
learning improves performance and results in transfer of what was learned to new situations. Also, past research has examined small-scale and short-term use of mobile learning. A number of mobile learning small-scale research projects have been conducted by Athabasca University (Woodill, 2011). These studies include a mobile workplace English project (www.wpeau.ca) which aimed to explore the effectiveness of mobile devices in delivering interactive and multimedia content for the development of English language skills. The project created and tested innovative approaches to mobile-assisted workplace language training. Moreover, Athabasca University Library has developed mobile-friendly websites with user interface features enabling access to resources from either a desktop, a laptop, or a mobile device. Other projects at AU have resulted in a mobile-friendly Digital Reading Room (DRR) offering course readings, mobile language websites including ESL grammar, and accent reduction instruction.

The large-scale mobile learning initiatives in the UAE, Thailand, Brazil, etc. are new and there were no opportunities to conduct research in the past to inform these new initiatives on best practices. It is critical that these large-scale initiatives conduct research to evaluate and guide implementation and to inform others of the best practices for mobile learning. However, the research must be well designed and must inform practice. Gunn \& Steel (2012) conducted a study to analyze past research on the use of learning technologies and the effectiveness of these research studies to inform practice. They used three criteria to select articles published in two journals from 2005 to 2012 and based on these criteria they selected 100 articles that met the criteria. The criteria used to select the articles comprised: (1) the research was conducted in higher education (2) The research was conducted to evaluate some aspect of technology supported learning design or the use of technology to solve an educational problem and (3) the research collected data and analyzed the data. After analyzing the articles, they found evidence of:

- poorly conceived or poorly applied methodologies;

- limited reference to theory;

- weak results;

- incomplete descriptions;

- uneven presentation of data;

- overblown and unsupported claims of impact and importance.

Research on mobile learning should avoid the pitfalls identified by Gunn \& Steel (2012). They suggest that the six guiding principles for research proposed by Shavelson \& Towne (2003, p. 55) should be used to guide quality research which can inform practice:

(1) Pose significant questions that can be investigated empirically;

(2) Link research to relevant theory;

(3) Use methods that permit direct investigation of the question;

(4) Provide a coherent and explicit chain of reasoning;

(5) Replicate and generalize across studies;

(6) Disclose research to encourage professional scrutiny and critique.

Cochrane (2012) identified the following gaps in research on mobile learning:

- No clear pedagogical theory for designing effective mobile learning;

- Limited evaluation of the mobile learning projects;

- A lack of longitudinal studies on mobile learning to determine how mobile learning is used in practical situations;

- Providing support for students in mobile learning;

Ally, M. (2013). Mobile learning: from research to practice to Impact Education. Learning and Teaching in

Higher Education: Gulf Perspectives, 10(2). http://lthe.zu.ac.ae 
- Providing support for teachers in mobile learning.

It appears that in the Gulf region as well as elsewhere, research on the following aspects is needed to successfully implement mobile learning to impact education:

- What cognitive process learners use when on the move and how to design learning materials when learning on the go;

- Learning styles in mobile contexts and which learning styles are more conducive to mobile learning.

- How to design for seamless learning where learners can carry learning sessions from one environment to another.

- How to internationalize the curriculum for global use in a global world.

- The characteristics of the current and upcoming generations and how to design and deliver for these generations; how to make interaction with mobile learning intuitive with effective interface design (Ally, 2012b; Wong, 2012). Users of mobile technologies should not have to refer to a print documents to learn how to use the technology: the access should be transparent.

- What policies, at the different country levels foster successful implementation of mobile learning.

- How to design information rich content for mobile technology delivery.

- The suitability of current mobile technologies for learning in the Gulf region. What are the characteristics of learning technology for different cultures? This is critical for universal and inclusive education, since most of the available mobile technologies were designed in a small number of countries.

- Building higher-order interaction in mobile learning to encourage higher-order learning.

- Strategies for developing hands-on training using mobile technology.

- How to design mobile learning materials; these should take advantage of the processing capabilities of the mobile technology and software to personalize the learning for the students. For example, Hsu and Ho (2012) developed a system that uses competency-based learning to evaluate the learners' needs. The system then uses carrier selection, fuzzy interpolation computation, and algorithm techniques to select the appropriate learning paths and objects so that the learning path can be adapted for individual learners.

\section{Benefits of Mobile Learning}

In developed countries there is a shift from desktop to mobile technology but in developing countries citizens are moving directly to mobile technology rather than acquiring desktop computers and then moving to mobile technology. This is an excellent opportunity for the education system to deliver learning materials to all citizens. The technology is impacting the way people work, learn, conduct business, interact with each other, and access information: mobile technologies allow people who do not have computers to access education.

People in developing countries who cannot afford expensive computers can move directly to mobile technology for formal and informal learning so that they can improve their education and quality of life. The use of mobile learning has been increasing over the last few years, with a rapid increase in developing countries which have the fastest growth rate in the acquisition of mobile technology. Mobile technology can be used for both formal and informal learning. In formal learning, students can use their mobile devices to access course materials while they are on the move or anytime they want to learn.

Ally, M. (2013). Mobile learning: from research to practice to Impact Education. Learning and Teaching in 
Ally and Stauffer (2008) completed a study where students had the option of accessing their course materials from anywhere and at anytime using their mobile devices. Results indicated that the majority of students felt that the use of the mobile device to access the course materials was useful and provided both flexibility and convenience. They also liked the convenience of being able to access the course work on the mobile device from wherever they were, and whenever they had time to learn.

Informal learning is learning that is not tied to a program of study and occurs on an ad hoc basis. Informal learning occurs when individuals want to improve themselves so that they can be productive in society and on the job and to develop themselves personally. Mobile learning which allows individuals to learn anywhere and at anytime has a major role to play in informal learning (Ally et al., 2008; Ally, 2012a; Clough et al., 2009). For example, completing language training to improve language skills to function on the job is an excellent application of mobile learning. Ally et al. (2008) conducted a study to determine the effectiveness of using mobile phones to deliver English as a Second Language (ESL) training to new immigrants. Students expressed a positive experience using the mobile phone to learn English grammar. They indicated that the use of mobile technology for ESL would be a good supplementary medium for learning at such times as waiting for a bus or travelling on a train, or whenever there was some spare time available. Using mobile devices to access the online course content increases motivation and opportunity for learning. Having the content online and right at students' fingertips, just one click away, means they can learn wherever they are, despite the constraints of busy daily schedules, commuting, etc.

Mobile technology can facilitate contextual and problem-based learning by detecting a learner's presence in a particular place, or in relation to other people and objects nearby, and adapting the learning experience accordingly (Kukulska-Hulme, 2010). In the workplace, people can learn within the context of their work on real-world problems. In their communities, learners can use mobile technology to obtain current information and to collaborate with other learners.

Using mobile technology allows learners to use the communication capabilities of the technology to network with people around the world so that they learn from each other and share information. Special needs students and students in remote locations can feel connected and empowered to learn using the technology.

\section{Challenges when implementing mobile learning}

The biggest barrier to the use of mobile learning in education is people's attitude towards the use of mobile technology in education. Educators see mobile technology as being too small to be useful, bringing too much distraction for learners, and associated with inappropriate behavior (UNESCO, 2012). Educators must be trained in how to implement mobile technology effectively in education. Learners must use the emerging technology so that they can be prepared to work in the $21^{\text {st }}$ Century world. Skills such as collaboration, communication, and digital literacy are required for the $21^{\text {st }}$ century learner and worker (UNESCO, 2012); these skills can be developed when students learn using mobile technologies.

Common barriers to education in some countries include remoteness, cost and lack of qualified teachers and education infrastructure. For example, countries in Latin America are facing the challenges of high drop-out rates, limited access to technology, and lack of teacher training programs which are preventing these countries from educating all citizens to become productive and to improve their quality of life. A common reason why education cannot be provided for more students is because of the lack of teachers and funding to build and maintain schools. Rather than building classrooms and acquiring more teachers, there is the possibility to deliver education on mobile technology so that learners can learn

Ally, M. (2013). Mobile learning: from research to practice to Impact Education. Learning and Teaching in

Higher Education: Gulf Perspectives, 10(2). http://lthe.zu.ac.ae 
from anywhere and can be tutored by experts in their local community or by teachers using communication technologies. The educational sectors in Latin America are starting to investigate the use of mobile learning to help address these challenges (UNESCO, 2012). However, in order for mobile learning to be effective, it must be developed and implemented properly. Education providers must rethink how materials and activities are designed and delivered. Current pedagogical approaches are not appropriate for mobile learning and for the new generations of learners: there must be an instructional paradigm shift that promises to fundamentally change the way students learn (UNESCO, 2012).

To help overcome the barriers to mobile learning, teachers must be trained in their new role as mobile learning facilitator. They must have a basic understanding of the technology and their features and how to develop effective learning strategies for mobile learning where learning is learner-centered rather than teacher-centered. Rather than trying to fit the new devices into the same instructional strategies, teachers should be thinking critically about how they will deliver instruction differently using the opportunities afforded by mobile technologies (UNESCO, 2102).

\section{Future directions for research and development on mobile learning in the Gulf}

There are many start-up mobile learning projects in the Gulf region. Two large scale projects, referred to above, are the iPad initiative in the United Arab Emirates and the workplace mobile learning project in the State of Qatar. A recent workshop on the directions that mobile learning research should take in the Gulf region suggested a number of directions for the future (Ally \& Santos, 2013). These are listed below.

- Develop learning materials for delivery on mobile technology with different operating systems since students have a variety of mobile technologies (even in contexts where one technology such as the iPad is officially supported). In some cases, students may have multiple mobile devices with different operating systems. In addition, learning materials must be developed for delivery on different ICTs including desktop computers, notebooks, tablets, and smart phones. This will provide flexibility for learners to learn anywhere and at anytime with any device.

- In organizations where students have to/can bring their own devices (BYOD) to the institution, there should be studies of the types of devices students bring and how students use the devices for learning during school hours and outside of school hours. It would be interesting to compare two groups, a BYOD group and a group provided with one particular mobile device, to determine the differences in use of the mobile devices and impact on attitude and performance.

- Most studies to date have been short-term, looking at students' attitudes towards use of mobile technology for learning. Given the institutional use of devices such as the iPad in UAE higher education, there should be longer-term studies on the impact of mobile learning on students' performance and how the use of mobile technology develops ICT and learning skills for the future.

- There is a need to design mobile learning materials and delivery systems for students with different learning styles; for example, different cultures may favour certain ways to learn. A learning style instrument should be used to determine students learning styles and mobile learning materials should be developed to cater for the different learning styles. For example, some cultures may prefer multimedia while other cultures may prefer text-based learning.

- Mobile learning in the Gulf region is currently implemented using a blended approach. There could be blending within a course where students complete part of the using mobile technology

Ally, M. (2013). Mobile learning: from research to practice to Impact Education. Learning and Teaching in

Higher Education: Gulf Perspectives, 10(2). http://Ithe.zu.ac.ae 
and part of the course is face-to-face. The other method is blending between courses, where some courses are delivered using mobile technology while some are delivered face-to-face. Research is needed to determine which courses can are suitable for the blended approach.

- As more open education resources (OERs) become available, organizations will have to determine how to select and include OERs in mobile learning courses. At the same time, students should be trained on how to research and use quality OERs to enhance their learning.

- Developers of mobile learning materials should explore the capabilities of the mobile technology to develop interactive learning materials to promote higher-order learning. These include interactive strategies such as games, simulation, interactive tutorial, problem-based learning, student-generated content, and peer-to-peer tutoring.

\section{Conclusion}

Mobile technology is impacting different sectors of society and will have a major role to play in the future of education. Mobile learning will be the future of education whether we like it or not: future generations of learners will demand that education be delivered on mobile technology. However, to realize the full potential of mobile learning, education must become learner-centered, with the learner able to access learning materials from any location and at anytime. There must be a sense of urgency in education to start using mobile technology to deliver education. Educational organizations' strategic and education plans must include strategies for implementing mobile learning since in the very near future mobile technology will largely replace desktop and laptop computers.

Mobile technology is profoundly changing the way people work, learn, conduct business, interact with each other, and access information. With mobile web usage expected to double within five years and to overtake PC access to the web, we have entered the mobile era. In the near future we will be moving into the 'Education 3.0' era where education will make use of semantic web technologies, provide ubiquitous service and access, personalize the information for individual learners, provide virtual services, and deliver learning materials specific to locations, resulting in location-based learning. Learning will become more problem-based, which will allow learners to learn in context and promote higher-order learning. Mobile and emerging technologies will allow ubiquitous access to information and learning materials, whereby citizens of the world can access learning materials from anywhere and at anytime. The technology will exist everywhere, giving learners' seamless access to learning materials. The learning space is moving away from the classroom at a specific time to anyplace and anytime.

Some likely trends in education include: the role of the teacher will change; learning will occur 24/7; learning materials will be available as open education resources; education will become globalized; learning will be more learner-centered; technology will change, resulting in ubiquitous access; new generations will not be able to function in the current traditional education system and will demand a more flexible and inclusive system. Learning will be pervasive: learners will not have to take the technology with them but the technology will be embedded everywhere (Vinu et al., 2011). The technology may also be non-physical or invisible, with many implications for how learning materials are designed and delivered for the future.

Mobile learning is 'green' learning since it reduces the use of print and minimizes travel.

Ally, M. (2013). Mobile learning: from research to practice to Impact Education. Learning and Teaching in

Higher Education: Gulf Perspectives, 10(2). http://lthe.zu.ac.ae 


\section{References}

Ally, M. (2009). Mobile learning: transforming the delivery of education and training. Athabasca: AU Press.

Ally, M., (2012a). Pocketful of new-age learning. The Human Factor, 2(12), 42-43.

Ally, M., (2012b). Designing mobile learning for the user. In Badrul Khan (Ed.), User interface design for virtual environments: challenges and advances. Hershey, PA: Information Science Reference (pp. 226235).

Ally, M. \& Santos, I. (2013). Researching mobile learning in your context. Workshop presented at the Mobile Learning: Gulf Perspectives Symposium, Abu Dhabi, April 2013.

Ally, M. \& Samaka, M. (2013). Improving communication skills in the workplace using mobile learning. Presentation at the UNESCO Second Mobile Learning Week. February 2013, Paris.

Ally, M. \& Stauffer, K. (2008). Enhancing mobile learning delivery through exploration of the learner experience. Paper presented at the 5th International Conference on Wireless, Mobile and Ubiquitous Technologies in Education (WMUTE2008). Beijing, China, March 2008.

Ally, M., McGreal, R., Schafer, S., Tin, T., \& Cheung, B. (2008). Use of a mobile digital library for mobile learning. In G. Needham \& M. Ally (Eds.), M-libraries: libraries on the move to provide virtual access. London: Facet Publishing (pp. 217-228).

Aubusson, P., Schuck, S., \& Burden, K. (2009). Mobile learning for teacher professional learning: benefits, obstacles and issues. ALT-J: Research in Learning Technology, 17(3), November 2009, 233247.

Bosomworth, D. (2013). Mobile marketing statistics 2013. Retrieved March 27, 2013 from http://www.smartinsights.com/mobile-marketing/mobile-marketing-analytics/mobile-marketingstatistics/

Cavus, N. \& Uzunboylu, H. (2009). Improving critical thinking skills in mobile learning. Procedia: Social and Behavioral Sciences, 1, 434-438.

Cheon, J., Sangno, L., Crooks, S.M. \& Song, J. (2012). An investigation of mobile learning readiness in higher education based on the theory of planned behavior. Computers \& Education, 59, 1054-1064.

Clough, G., Jones, A., McAndrew, P., \& Scanlon, E. (2009). Informal learning evidence in online communities of mobile device enthusiasts. In M. Ally (Ed.), Mobile learning: transforming the delivery of education and training. Athabasca: AU Press.

Cochrane, T.D. (2010). Exploring mobile learning success factors. ALT-J: Research in Learning Technology, 18(2), July 2010, 133-148.

Cochrane, T.D. (2012). Critical success factors for transforming pedagogy with mobile Web 2.0. British Journal of Educational Technology, 43(1), 1-21.

Corbeil, J.E. \& Corbeil, M.E. (2011). Are we ready for mobile learning now? 2007 mobile learning predictions revisited. Issues in Information Systems, XII(2), 142-152.

Faille, M. \& Morrison, K. (2013). Rise of the mobile phone. National Post, April 5, 2013. http://news.nationalpost.com/2013/04/05/graphic-rise-of-the-mobile-phone/ 
Fernández-López, A., Rodríguez-Fórtiz, M.J., Rodríguez-Almendros, M.L., Martínez-Segura, M.J. (2013). Mobile learning technology based on iOS devices to support students with special education needs. Computers \& Education, 61, 77-90.

Gitsaki, C., Robby, M., Priest, T., \& Ben-Chabane, Y. (2013). Researching the UAE iPad Initiative. Plenary presented at the Mobile Learning: Gulf Perspectives Symposium, Abu Dhabi, April 2013.

Gunn, C. \& Steel, C. (2012). Linking theory to practice in learning technology research. Research in Learning Technology, 20, 1-14.

Hsu, C. \& Ho, C. (2012). The design and implementation of a competency-based intelligent mobile learning system. Expert systems with applications, 30, 8030-8043.

Jones, A.C., Scanlon, E., \& Clough, G. (2013). Mobile learning: two case studies of supporting inquiry learning in informal and semiformal settings. Computers \& Education, 61, 21-32.

Kamali, T.A. (2013). Mobile learning from a government perspective. Panel member, UNESCO Second Mobile Learning Week. Paris, 2013.

Kinash, S., Brand, J., \& Mathew, T. (2012). Challenging mobile learning discourse through research: Student perceptions of Blackboard Mobile Learn and iPads. Australasian Journal of Educational Technology, 28(4), 639-655.

Kukulska-Hulme, A. (2010). Learning cultures on the move: where are we heading? Educational Technology and Society, 13(4), 4-14.

Lai, H., Chang, C., Li, W., Fan, Y., Wu, Y. (2013). The implementation of mobile learning in outdoor education: application of QR codes. British Journal of Educational Technology, 44(2), E57-E62.

Mahat, J., Ayub, A.F.M., \& Wong, S.L. (2012). An assessment of students' mobile self-efficacy, readiness and personal innovativeness towards mobile learning in higher education in Malaysia. Procedia Social and Behavioral Sciences, 64(9), 284-290.

Mims, C. (2011, 1 July). Samsung windfall: all of South Korea's textbooks to go digital by 2015. MIT Technology Review. http://www.technologyreview.com/blog/mimssbits/26960/

Ng, W. \& Nicholas, H. (2012). A framework for sustainable mobile learning in schools. British Journal of Educational Technology, 43(1), 1-21.

Quinn, C. (2010). Writing and the $4 C^{\prime}$ s of mobile. http://blog.learnlets.com/?p=1459

Park, S.Y., Nam, M., \& Cha, S. (2012). University students' behavioral intention to use mobile learning: evaluating the technology acceptance model. British Journal of Educational Technology, 43(4), 592605.

Pollara, P. \& Kee Broussard, K. (2011). Student perceptions of mobile learning: a review of current research. Proceedings of Society for Information Technology \& Teacher Education International Conference 2011 (pp. 1643-1650). Chesapeake, VA: AACE.

Shavelson, R. \& Towne, L. (Eds.). (2003). Scientific research in education. Washington, DC: National Academies Press.

Taleb, Z. \& Sohrab, A. (2012). Learning on the move: the use of mobile technology to support learning for university students. Procedia - Social and Behavioral Sciences, 69, 1102-1109. 
Terras, M.M. \& Ramsay, J. (2012). The five central psychological challenges facing effective mobile learning. British Journal of Educational Technology, 43(5), 820-832.

UNESCO (2012). Working paper series on mobile learning: turning on mobile learning in Latin America. Paris: UNESCO.

Vinu, P.V., Sherimon, P.C., \& Reshmy, K. (2011). Towards pervasive mobile learning: the vision of 21st century. Procedia: Social and Behavioral Sciences, 15, 3067-3073.

Wang, M. \& Shen, R. (2012). Message design for mobile learning: learning theories, human cognition and design principles. British Journal of Educational Technology, 43(4), 561-575.

Wong, L. (2012). A learner-centric view of mobile seamless learning. British Journal of Educational Technology, 43(1), E19-E23.

Woodill, G. (2011, February 10). Re: Mobile Learning in Canada [Web log post]. Retrieved from http://www.mobilelearningedge.com/2011/02/mobile-learning-in-Canada.

Yen, J., Lee, C., \& Chen, I. (2012). The effects of image-based concept mapping on the learning outcomes and cognitive processes of mobile learners. British Journal of Educational Technology, 43(2), 307320. 